\title{
ANÁLISE DO NÍVEL DE CONFORTO ACÚSTICO NA BIBLIOTECA DE UMA ESCOLA PÚBLICA
}

\section{A. S. Pereira, L. C. S. Silva e F. H. S. Sales}

Instituto Federal do Maranhão, Grupo de Pesquisa em Ensino de Física do IFMA c4rlos.sp@gmail.com - leilacristia@gmail.com - fsales@ifma.edu.br

\section{RESUMO}

O presente trabalho avaliou os níveis de ruído no ambiente interno da biblioteca Tebyreça de Oliveira do Instituto Federal de Educação, Ciência e Tecnologia do Maranhão (IFMA), campus Monte Castelo, e suas influências no desempenho de estudo dos estudantes que a freqüentam. Os níveis encontrados foram comparados aos valores da norma regulamentadora que trata dos níveis de ruído para o conforto acústico.

PALAVRAS-CHAVE: Acústica, Ruídos Sonoros, Biblioteca.

\section{ANALYSIS OF THE LEVEL OF COMFORT NOISE IN THE LIBRARY OF A PUBLIC SCHOOL}

\section{ABSTRACT}

This study assessed the levels of noise in the internal environment of the library Tebyreça de Oliveira of the Federal Institute of Education, Science and Technology of the Maranhão (IFMA), Monte Castelo campus, and their influences on the performance study of students who attend. The levels found were compared with values of the regulation dealing with noise levels for acoustic comfort.

KEY-WORDS: Acoustic, Noise Sound, Library. 


\section{ANÁLISE DO NÍVEL DE CONFORTO ACÚSTICO NA BIBLIOTECA DE UMA ESCOLA PÚBLICA}

\section{INTRODUÇÃO}

A biblioteca é um ambiente de estudo e local onde os estudantes, quando não estão em sala de aula, passam grande parte do seu dia que por muitas vezes somente para conversar. Para assegurar a aprendizagem e a qualidade de vida é necessário que esse ambiente seja salubre e confortável, a fim de garantir o bem estar do indivíduo, sua segurança e produtividade. Reconhecer a importância de biblioteca para o aprendizado é um questionamento que constantemente se faz presente na vida do estudante e principalmente do ensino médio nas vésperas de suas realizações a universidade, sendo a mesma um campo de produção e conhecimento, na qual o aluno encontra a auto-imagem,auto-estima e autorealização.

As bibliotecas, de forma geral, são adaptações de prédios existentes que passam a ter estas funções, ainda que estes resultados não sejam os melhores. Alguns arquitetam um espaço que se resume basicamente em dois ambientes: o depósito de livros e o local de leitura, além de salas secundárias [1].Tornando-se desta forma um lugar inadequado para este lugar tão importante da escola, tendo a missão de servir seus usuários, oferecendo atividades de incentivo a leitura, como também recursos informacionais e serviços de apoio à aprendizagem.

A realidade das bibliotecas no Brasil, é que não sofreram adaptações com o passar dos anos, na questão do isolamento acústico, e seu conforto acústico é pouco estudado no Brasil. A ocorrência de níveis elevados de ruído nos ambientes fechados se deve às fontes geradoras de ruído, às características arquitetônicas do local como volumetria, revestimentos das superfícies e sistemas de vedação; ou então, ao ruído externo que interfere no ambiente, como por exemplo, o ruído de tráfego [2].

Um dos fatores que compromete a qualidade do ambiente de estudo é o ruído ocupacional excessivo. Os ruídos chegam a provocar uma redução de até $60 \%$ da produtividade por dificultar a concentração, propiciando erros, desperdícios ou acidentes por distração [3]. A exposição excessiva ao ruído pode comprometer outros órgãos e funções do organismo, além de causar perturbações no sono acarretando em efeitos como irritabilidade, cansaço, elevando os níveis de estresse e dificuldade de concentração [4].

Como se sabe, o ruído acima de $45 \mathrm{~dB}$ não é recomendado para as bibliotecas, onde este proporciona desconcentração do seu usuário, sendo assim, o nível de ruído pode ser um bom indicador de qualidade destes ambientes (NBR10152) [5]. Diante destas circunstâncias foram realizadas medidas dos níveis de ruído a que estão submetidos os estudantes, freqüentadores diários, da biblioteca Tebyreça de Oliveira do Instituto Federal de Educação, Ciência e Tecnologia do Maranhão - IFMA, campus Monte Castelo, localizado na cidade de São Luís do Maranhão. 


\section{METODOLOGIA}

Os procedimentos adotados no trabalho foram:

- Obtenção do equipamento de medição dos níveis de pressão sonora.

- Identificação das fontes de ruído.

- Definição dos padrões de medição adotados.

- Realização de três medições por dia, durante cinco dias.

- Sendo cinco medições em cada turno: manhã, tarde e noite.

○ Durante duas horas, cada turno, em intervalos de trinta minutos.

- Determinação do Nível de Pressão Sonora no interior da biblioteca.

- Análise gráfica dos dados tabelados.

- Comparação dos resultados obtidos com valores de referência - NBR 10152

- Aplicação de questionários a respeito das condições de conforto acústico oferecidas pela biblioteca.

\section{Níveis de Ruído para Conforto Acústico - NBR 10152 - Dez 1987}

A Associação Brasileira de Normas Técnicas (ABNT), através da NBR-10.152, de dezembro de 1987, definiu os níveis de ruído compatíveis com o conforto acústico em diversos ambientes [6]. Nos últimos anos, os altos níveis de ruídos se transformaram em uma das formas de poluição que atinge grande número de pessoas. A poluição sonora não se restringe apenas às regiões de grande concentração industrial. A exposição ao ruído ocupacional é objeto de estudo de muitas pesquisas que visam classificar os níveis sonoros em certos ambientes de acordo com a atividade que é desenvolvida neste ambiente [7]. A NBR 10152 estabelece os níveis de ruído compatíveis com o conforto acústico em ambientes diversos.

A Tabela 1 apresenta os níveis sonoros para conforto acústico em certas localidades: 
Tabela 1 - Valores dB (A) para níveis de conforto acústico ${ }^{[5]}$.

\begin{tabular}{ll}
\hline \multicolumn{1}{c}{ Locais } & $\mathbf{d B}(\mathbf{A})$ \\
\hline Hospitais & $35-45$ \\
$-\quad$ Apartamentos, enfermarias, Berçários, Centros cirúrgicos. & $40-50$ \\
$-\quad$ Laboratório, Áreas para uso público. & $45-55$ \\
$-\quad$ Serviços. &
\end{tabular}

\section{Escolas}

- Bibliotecas, Salas de música, Salas de Desenho.

$35-45$

- Salas de aula, Laboratórios.

$40-50$

- Circulação.

$45-55$

\section{Hotéis}

- Apartamentos.

- Restaurantes, Salas de Estar.

$40-50$

- Portaria, Recepção, Circulação.

$45-55$

\section{Residências}

- Dormitórios.

$35-45$

- Salas de estar.

$40-50$

\section{Auditórios}

- Salas de concertos, Teatros.

$30-40$

- Salas de conferências, Cinemas, Salas de uso múltiplo.

$35-45$

\section{Escritórios}

$30-40$

- Salas de reunião.

$35-45$

- Salas de gerência, Salas de projetos e de administração.

$45-65$

- Salas de computadores.

$50-60$

- Salas de mecanografia.

Igrejas e Templos (Cultos meditativos)

$40-50$

\section{Locais para esportes}

- Pavilhões fechados para espetáculos e atividades esportivas

$45-60$

a) O valor inferior da faixa representa o nível sonoro para conforto, enquanto que o valor superior significa o nível sonoro aceitável para a finalidade.

b) Níveis superiores aos estabelecidos nesta tabela são considerados de desconforto, sem necessariamente implicar risco de dano à saúde.

Neste trabalho, serão considerados apenas os níveis de conforto acústico em escolas, já que o seu objeto de estudo é uma biblioteca, porém os níveis apresentados de outras localidades podem ser considerados em nível de comparação. 
Para a realização deste trabalho foram realizadas medições do nível de pressão sonora no interior da biblioteca do IFMA. O decibelímetro foi o equipamento utilizado para a realização destas medições (Figura 1)

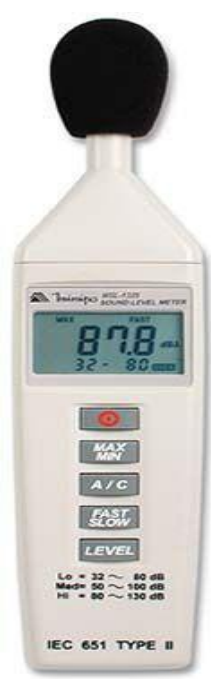

Figura 1 - Decibelímetro digital modelo MSLN -1325 utilizado nas medidas de níveis de ruídos no interior da Biblioteca.

\section{Estudo de Caso}

A Biblioteca Central Tebyreçá de Oliveira está distribuída em dois pavimentos (térreo e subsolo) cujo ambiente fornece o convívio com diferentes materiais informacionais. No ambiente térreo encontram-se a administração da biblioteca, acervo de livros, acervo de periódicos, salão de Leitura e Xerox. O subsolo dispõe de duas salas, sendo uma de estudos reservados e a outra com acervo de Monografias, Teses e Dissertações.

A Tabela 2 apresenta os elementos do acervo da biblioteca:

Tabela 2 - Acervo da biblioteca.
( $x$ ) Livros
(x) Periódicos
$(x)$ Jornais
( $x$ ) CD - ROMS

\begin{tabular}{l|c}
\hline Quantidadede funcionários & 14 \\
\hline Quantidade de computadores & 17 \\
\hline Quantidade de impressoras & 3 \\
\hline Quantidade de telefones & 3 \\
\hline Quantidade de usuários & 2542 \\
\hline Quantidade de livros & 4604 títulos \\
\cline { 2 - 2 } & 12864 exemplares \\
\hline Quantidade de CD-ROMS & $\approx 90$ \\
\hline
\end{tabular}


O desenvolvimento deste trabalho foi realizado com base no ambiente interno da biblioteca do IFMA, onde é possível constatar a presença de níveis de ruídos consideráveis. Com o intuito de quantificar estes níveis, foram realizadas medições durante uma semana, nos três turnos de funcionamento da biblioteca. As medições foram feitas durante duas horas, em cada turno, divididas em intervalos de trinta minutos.

As medições foram realizadas somente no salão de leitura, em um ponto central, como pode ser observado na Figura 2, que mostra a planta baixa do setor térreo da biblioteca:

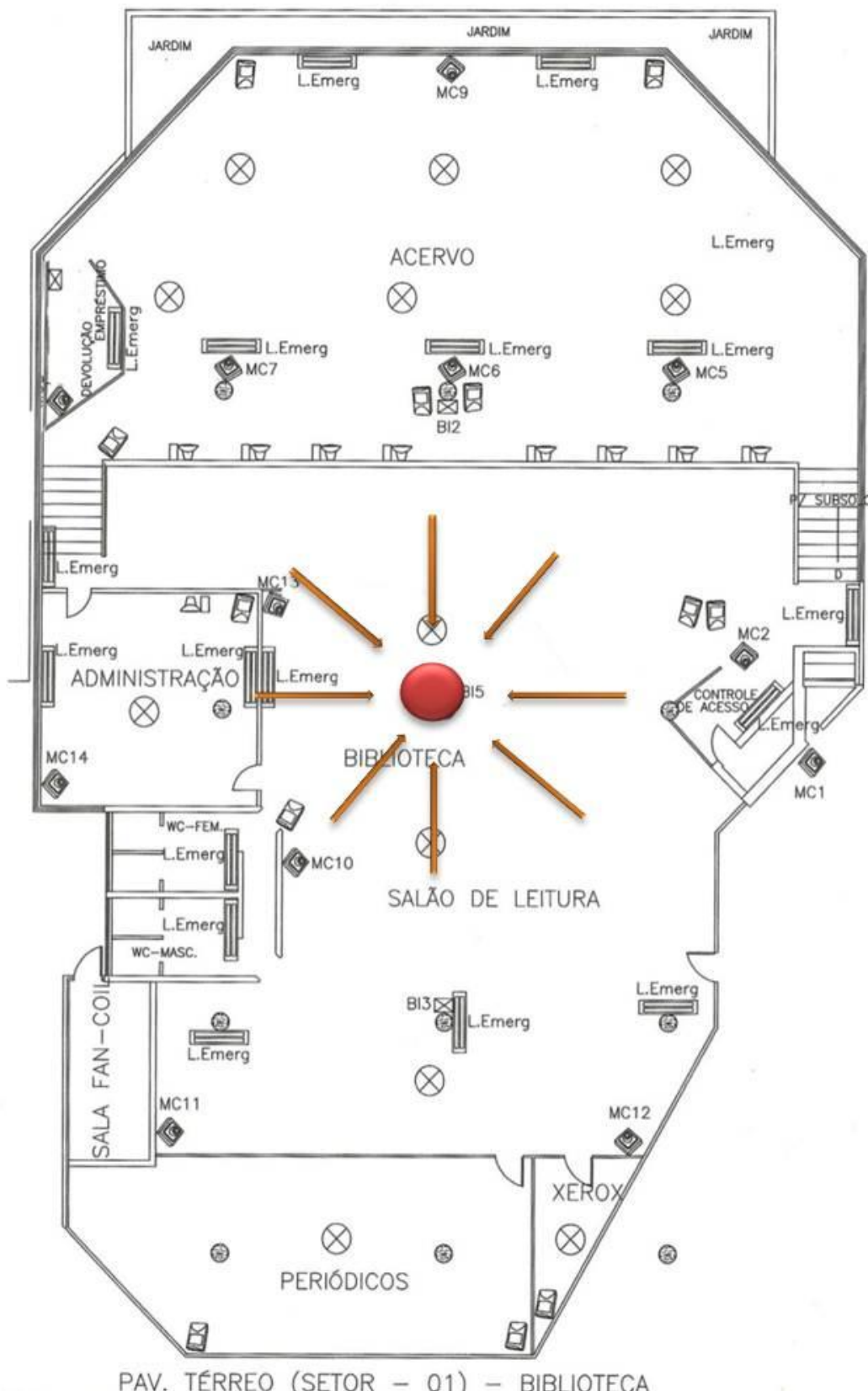

Figura 2 - Planta baixa da biblioteca do IFMA - Campus Monte Castelo. 


\section{Caracterização das fontes de ruído na biblioteca:}

- Ar-condicionado.

- Telefone da administração.

- Sirene externa.

- Impressoras

- Usuários

\section{RESULTADOS E DISCUSSÕES}

Após a coleta, os dados foram organizados, sendo apresentados em tabelas e gráficos, para facilitar a sua descrição e melhor apresentação do resultados obtidos. As tabelas foram organizadas em três colunas referentes aos turnos da manhã, tarde e noite, onde cada coluna contém os valores mínimo e máximo de cada medição de acordo com o horário em que foi realizada. A primeira coluna de cada tabela mostra a número da respectiva medida, num total de cinco, referente a cada turno.

Os gráficos apresentam uma perspectiva de visualização que possibilita, de forma clara, observar a faixa em que se encontram os níveis de pressão sonora mensurados.

\section{Primeiro Dia}

A Tabela 3 apresenta os valores de níveis de ruídos obtidos no primeiro dia:

Tabela 3 - Medições do primeiro dia.

\begin{tabular}{c|c|c|c|c|c|c}
\cline { 2 - 7 } & \multicolumn{2}{c|}{ MANHÃ } & \multicolumn{2}{c}{ TARDE } & \multicolumn{2}{c}{ NOITE } \\
\cline { 2 - 7 } & \multicolumn{3}{c}{ MPS (dB) } \\
\cline { 2 - 7 } & MÍN & MAX & MÍN & MAX & MíN & MAX \\
\hline 1 & 57,1 & 67,8 & 57,6 & 66,5 & 61,2 & 69,2 \\
\hline 2 & 56,5 & 61,5 & 57,8 & 65,9 & 57,2 & 61,8 \\
\hline 3 & 57,8 & 62,6 & 59,3 & 64,5 & 61,8 & 65,4 \\
\hline 4 & 56,5 & 60,7 & 59,3 & 68,5 & 57,9 & 70,5 \\
\hline 5 & 58,5 & 64,1 & 59,1 & 64,3 & 57,9 & 64,3 \\
\hline
\end{tabular}


A Figura 3 mostra a relação entre valores de níveis de ruído máximo e mínimo mensurados no período da manhã:

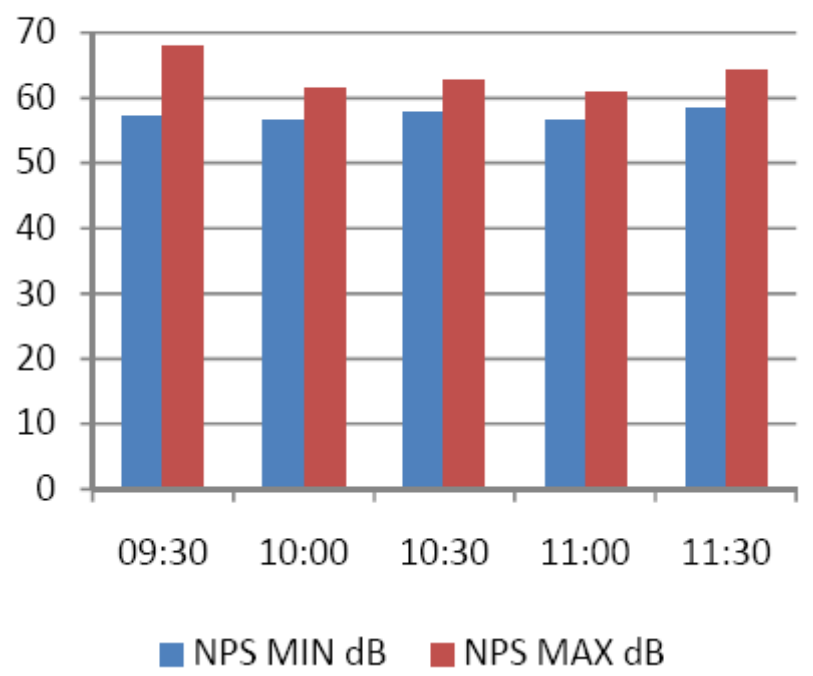

Figura 3 - Relação entre valores de níveis de ruídos máximo e mínimo mensurados no período da manhã.

A Figura 4 apresenta a relação entre valores mensurados no período da tarde:

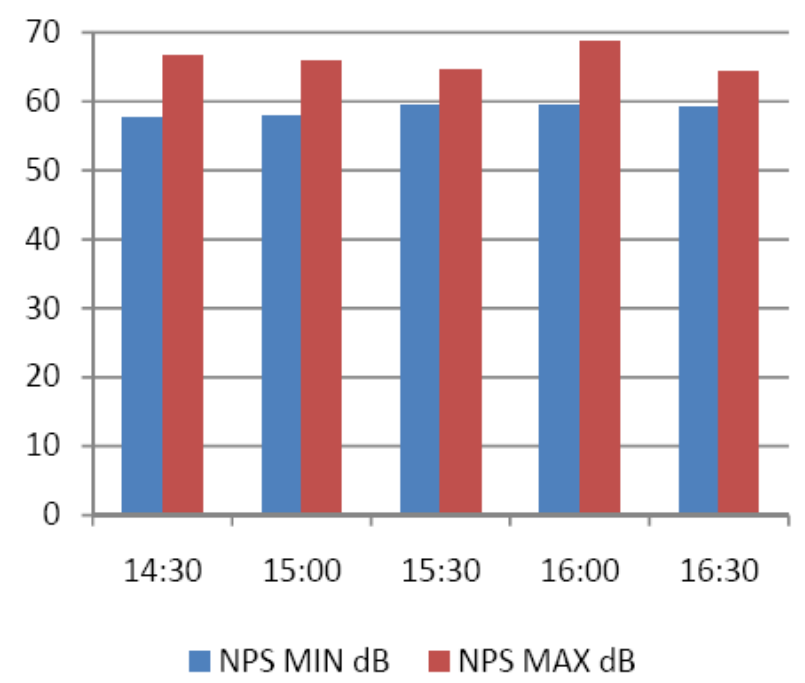

Figura 4 - Relação entre valores de níveis de ruídos máximo e mínimo mensurados no período da tarde. 
A Figura 5 mostra a relação entre valores mensurados no período da noite:

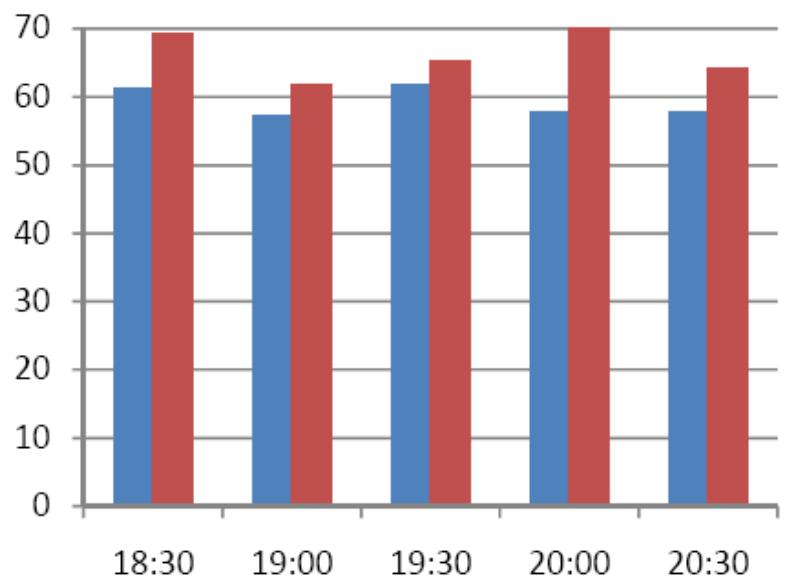

NPS MIN dB $\quad$ NPS MAX dB

Figura 5 - Relação entre valores de níveis de ruídos máximo e mínimo mensurados no período da noite.

Neste primeiro dia, com média de 25 pessoas freqüentando a biblioteca, foi possível notar que os valores mensurados apresentam um padrão dentro de determinadas faixas. Nos turnos da manhã, tarde e noite os mínimos estiveram entre 56,5 a $60,7 \mathrm{~dB}$ 's. Os valores máximos, nos três turnos, apresentaram comportamento valores entre 60,5 a 70,5 dB's.

\section{Segundo Dia}

A Tabela 4 mostra os valores obtidos no segundo dia:

Tabela 4 - Medições do segundo dia.

\begin{tabular}{|c|c|c|c|c|c|c|}
\hline & \multicolumn{2}{|c|}{ MANHÃ } & \multicolumn{2}{|c|}{$\overline{\text { TARDE }}$} & \multicolumn{2}{|c|}{ NOITE } \\
\hline & \multicolumn{6}{|c|}{ NPS (dB) } \\
\hline & MíN & MÁX & MíN & MÁX & MíN & $\overline{M A ́ X}$ \\
\hline 1 & 62,4 & 69,6 & 56,7 & 59,5 & 58 & 60,3 \\
\hline 2 & 58 & 61,5 & 57,1 & 60,8 & 57,9 & 59,8 \\
\hline 3 & 57,6 & 60,6 & 58,6 & 63,8 & 57,5 & 62 \\
\hline 4 & 58,2 & 63,9 & 59,4 & 62,8 & 58 & 61,5 \\
\hline 5 & 55,9 & 61,4 & 59 & 64,5 & 56,9 & 58,6 \\
\hline
\end{tabular}


A Figura 6 apresenta a relação entre valores mensurados pela manhã:

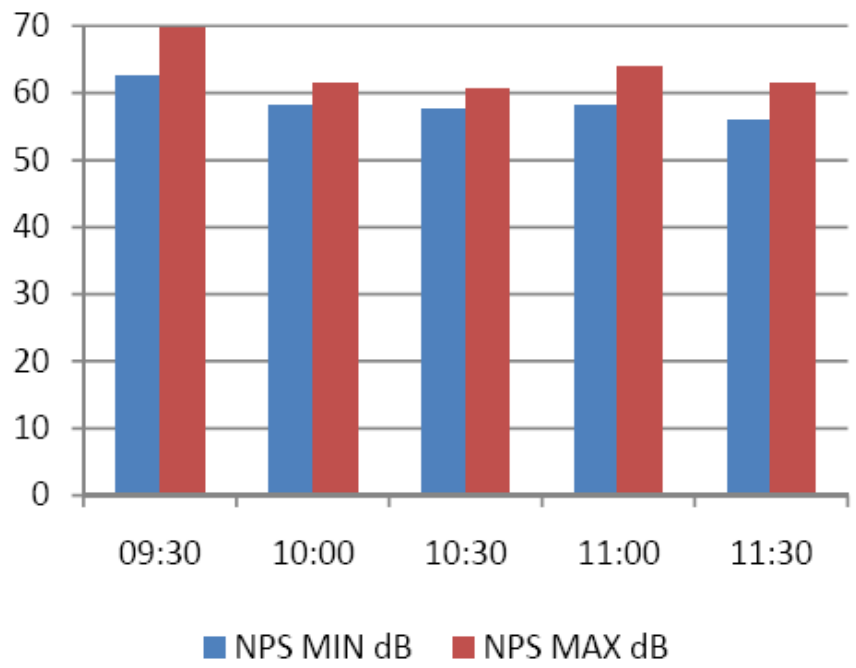

Figura 6 - Relação entre valores de níveis de ruídos máximo e mínimo mensurados no período da manhã.

A Figura 7 mostra a relação entre os valores mensurados no período da tarde:

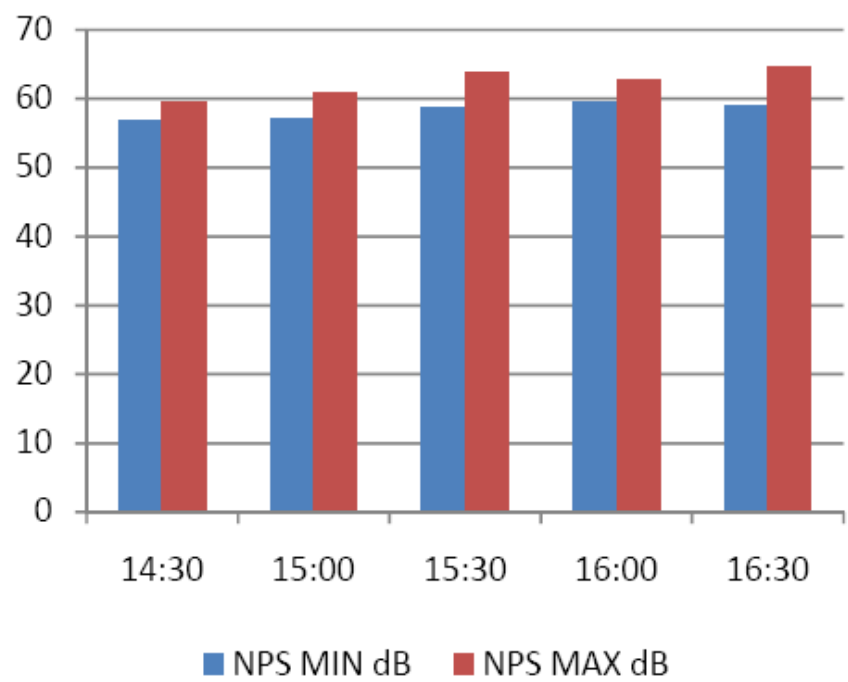

Figura 7 - Relação entre valores de níveis de ruídos máximo e mínimo mensurados no período da tarde.

A Figura 8 exibe a relação entra os valores mensurados no período da noite: 


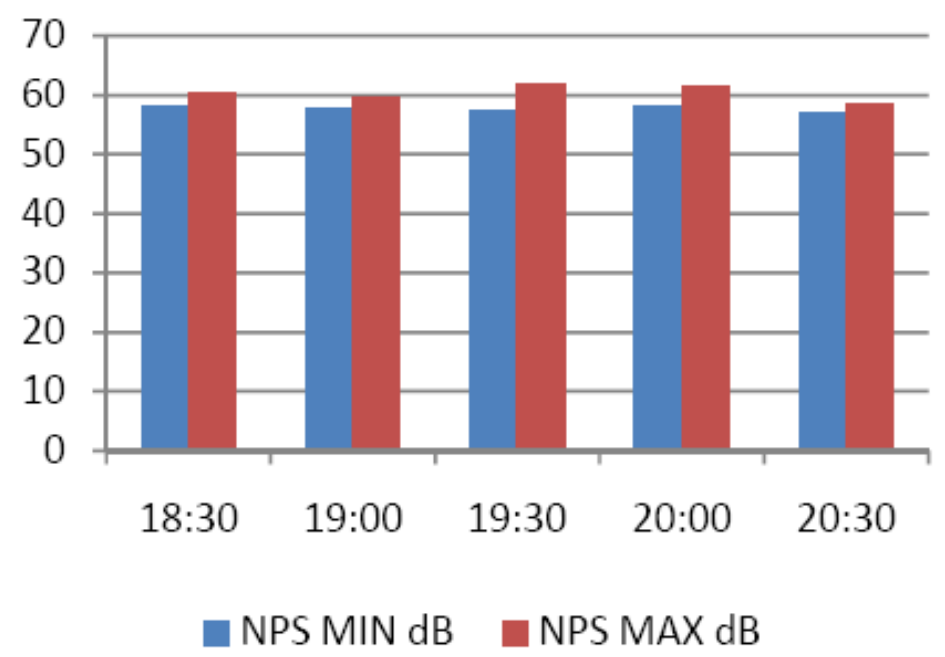

Figura 8 - Relação entre valores de níveis de ruídos máximo e mínimo mensurados no período da noite.

Durante o segundo dia, houve em média 26 freqüentadores nos horários em que foram realizadas as medições. Os resultados se mostraram semelhantes aos do primeiro dia com relação à faixa de valores apresentada. Os mínimos se mantiveram entre de 55,9 a 62,4 dB's nos três turnos. Os máximos estiveram na faixa de valores entre 58,6 a 69,6 dB's nos períodos da manhã, tarde e noite. Um detalhe importante, é que foi possível captar o nível de pressão sonora emitido pela sirene que marca a troca de horários, dentro da biblioteca chegou a um pico de 70,4 dB. 


\section{Terceiro Dia}

A Tabela 5 apresenta os valores das medições obtidos no terceiro dia:

Tabela 5 - Medições do terceiro dia.

\begin{tabular}{c|c|c|c|c|c|c}
\cline { 2 - 7 } & \multicolumn{2}{c|}{ MANHÃ } & \multicolumn{2}{c}{ TARDE } & \multicolumn{2}{c}{ NOITE } \\
\cline { 2 - 7 } & \multicolumn{4}{c}{ MPS (dB) } \\
\cline { 2 - 7 } & MÍN & MÁX & MÍN & MÁX & MÍN & MÁX \\
\hline 1 & 56 & 58,5 & 58,2 & 60,4 & 58,3 & 66,8 \\
\hline 2 & 57,4 & 60,8 & 60,6 & 65,7 & 60,1 & 65,3 \\
\hline 3 & 58,1 & 59,3 & 59,4 & 63,1 & 59,3 & 63,7 \\
\hline 4 & 57,2 & 65,9 & 57,1 & 62,2 & 58,6 & 65,9 \\
\hline 5 & 58,8 & 61,4 & 59,3 & 64,1 & 57,5 & 62,2 \\
\hline
\end{tabular}

A Figura 9 apresenta a relação entre os valores mensurados pela manhã:

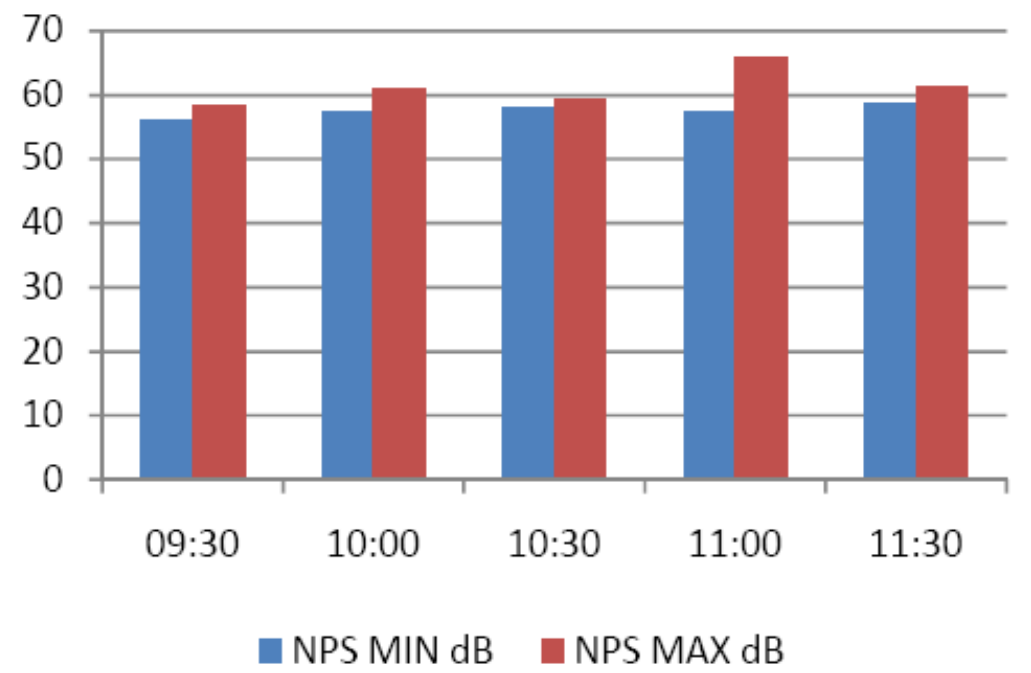

Figura 9 - Relação entre valores de níveis de ruídos máximo e mínimo mensurados no período da manhã.

A Figura 10 mostra a relação entre os valores mensurados no período da tarde: 


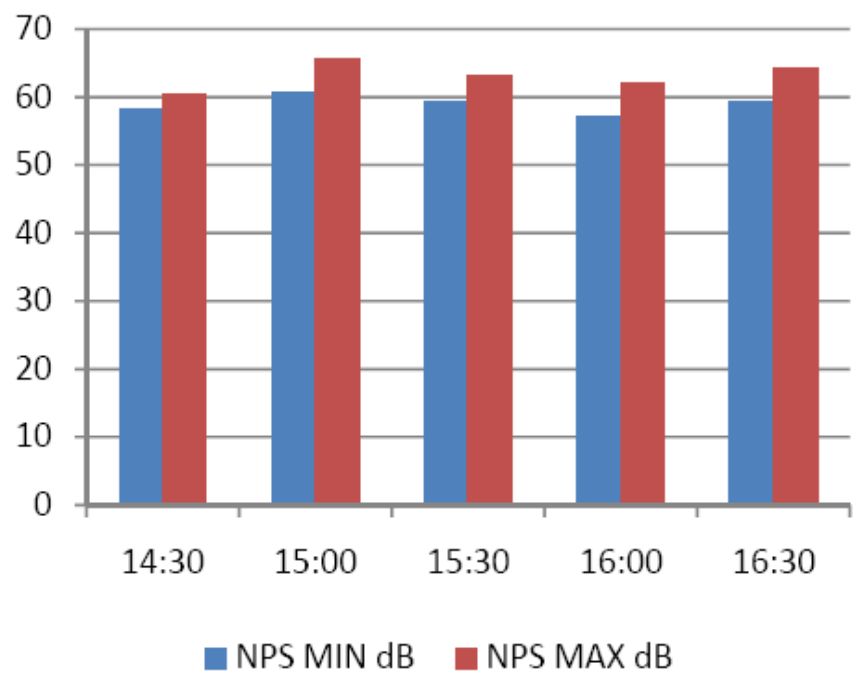

Figura 10 - Relação entre valores de níveis de ruídos máximo e mínimo mensurados no período da tarde.

A Figura 11 apresenta a relação entre os valores obtido no período da noite:

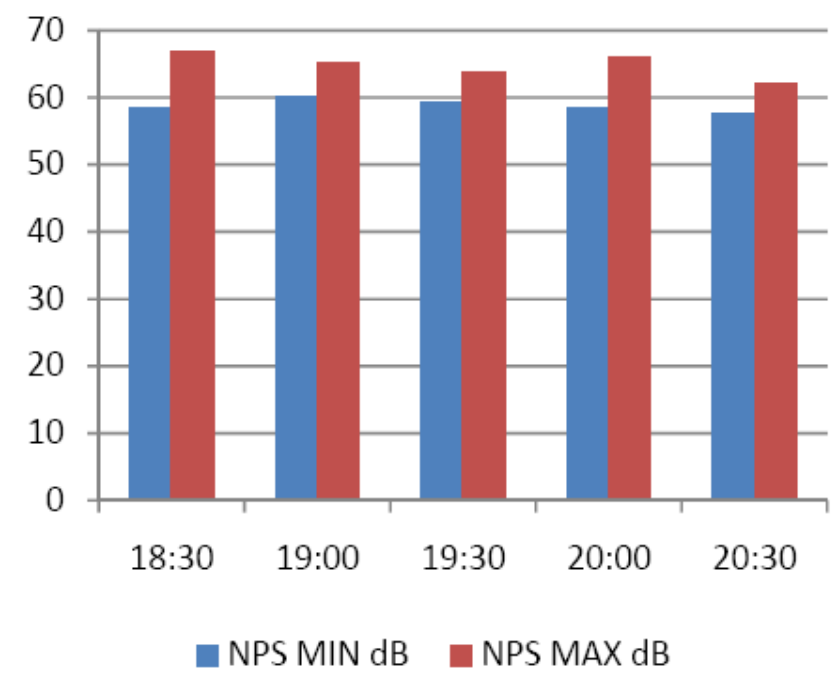

Figura 11 - Relação entre valores de níveis de ruídos máximo e mínimo mensurados no período da noite.

Com 24 pessoas, em média, freqüentando a biblioteca durante as medições do terceiro dia, os valores obtidos apresentaram valores, em média a faixa de valores permaneceu idêntica. Os mínimos ficaram entre 56 e 60,6 dB's, já o valores máximos entre 58,5 e $66,8 \mathrm{~dB}^{\prime}$ s. 


\section{Quarto Dia}

A Tabela 6 apresenta os valores obtidos nas medições do quarto dia:

Tabela 6 - Medições do quarto dia.

\begin{tabular}{c|c|c|c|c|c|c}
\cline { 2 - 7 } & \multicolumn{2}{c|}{ MANHÃ } & \multicolumn{2}{c}{ TARDE } & \multicolumn{2}{c}{ NOITE } \\
\cline { 2 - 7 } & \multicolumn{4}{c}{ MPS (dB) } \\
\cline { 2 - 7 } & MÍN & MÁX & MÍN & MÁX & MÍN & MÁX \\
\hline 1 & 58,1 & 65,6 & 56,9 & 59,5 & 55,4 & 58 \\
\hline 2 & 56,7 & 59,2 & 59,9 & 62,5 & 54,9 & 56,5 \\
\hline 3 & 56,5 & 58,5 & 59,3 & 65,1 & 56,1 & 60,8 \\
\hline 4 & 57,7 & 63,4 & 50,7 & 55,8 & 57 & 63,3 \\
\hline 5 & 58,1 & 60,6 & 53,3 & 59,3 & 56,1 & 61,7 \\
\hline
\end{tabular}

A Figura 12 mostra a relação entre os valores obtidos pela manhã:

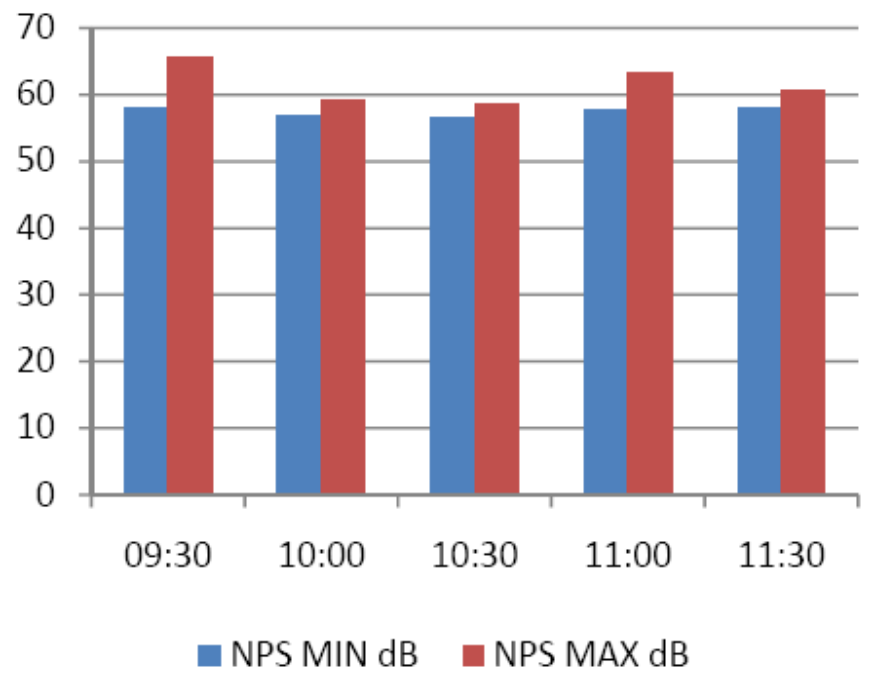

Figura 12 - Relação entre valores de níveis de ruídos máximo e mínimo mensurados no período da manhã.

A Figura 13 apresenta a relação entre os valores obtidos no período da tarde: 


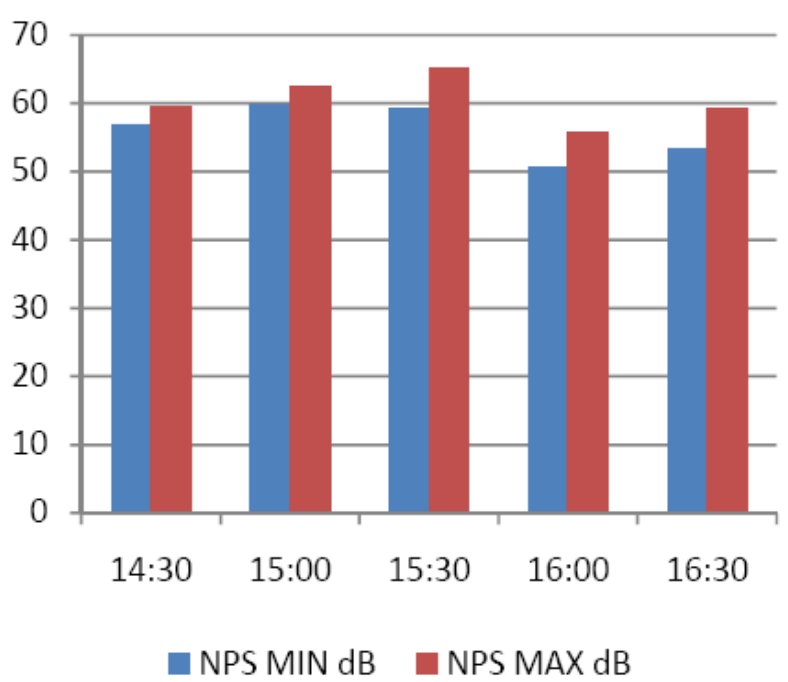

Figura 13 - Relação entre valores de níveis de ruídos máximo e mínimo mensurados no período da tarde.

A Figura 14 exibe a relação entre os valores obtidos no período noturno:

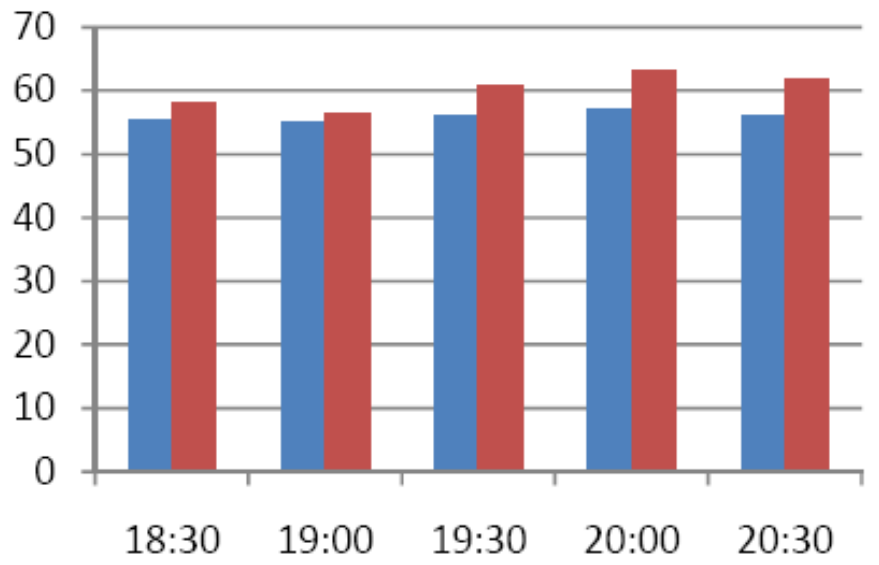

- NPS MIN dB $\quad$ NPS MAX dB

Figura 14 - Relação entre valores de níveis de ruídos máximo e mínimo mensurados no período da noite.

No penúltimo dia, com 24 pessoas freqüentando a biblioteca, os valores mínimos estiveram entre 50,7 e 59,9 dB's, já os valores máximos oscilaram entre 55,8 e 65,6 dB's. 


\subsection{Quinto Dia}

A Tabela 7 mostra os valores obtidos das medições no quinto dia:

Tabela 7 - Medições do quinto dia.

\begin{tabular}{c|c|c|c|c|c|c}
\cline { 2 - 7 } \multicolumn{1}{c|}{} & \multicolumn{4}{c|}{ MANHÃ } & \multicolumn{2}{c}{ NARDE } \\
\cline { 2 - 7 } & \multicolumn{3}{c}{ NPS (dB) } \\
\cline { 2 - 7 } & MÍN & MÁX & MÍN & MÁX & MÍN & MÁX \\
\hline 1 & 58,6 & 65,4 & 56,3 & 57,6 & 58,1 & 60,3 \\
\hline 2 & 57,2 & 60,3 & 57,7 & 60,2 & 55,3 & 63,6 \\
\hline 3 & 59,4 & 63,8 & 56,6 & 58,3 & 56,8 & 60,9 \\
\hline 4 & 55,6 & 59,6 & 58 & 59,7 & 55,1 & 59,7 \\
\hline 5 & 57 & 62 & 58,1 & 61 & 55,6 & 56,5 \\
\hline
\end{tabular}

A Figura 15 mostra a relação entre as medidas do turno matutino:

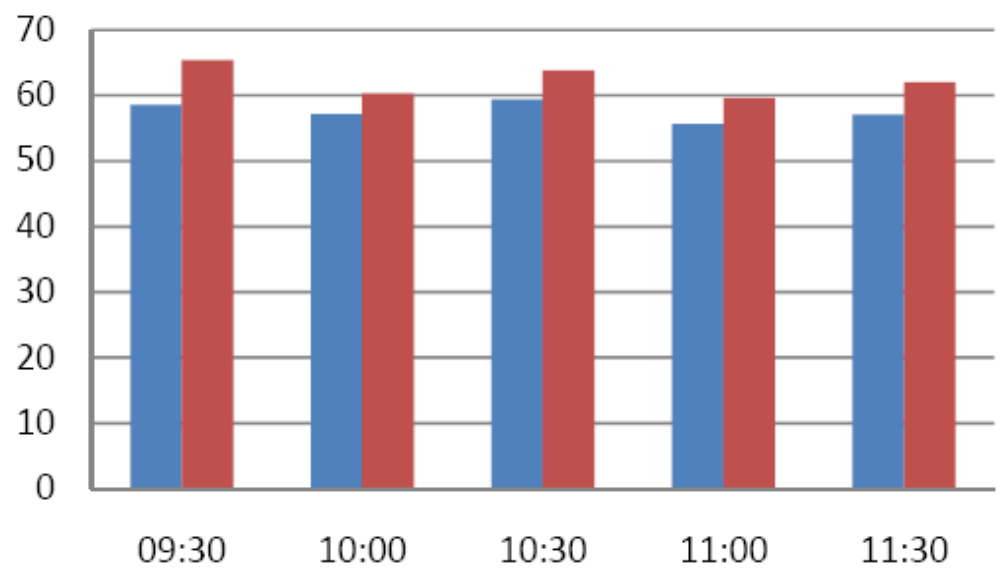

NPS MIN dB $\quad$ NPS MAX dB

Figura 15 - Relação entre valores de níveis de ruídos máximo e mínimo mensurados no período da manhã.

A Figura 16 apresenta a relação entre os valores obtidos no turno da tarde: 


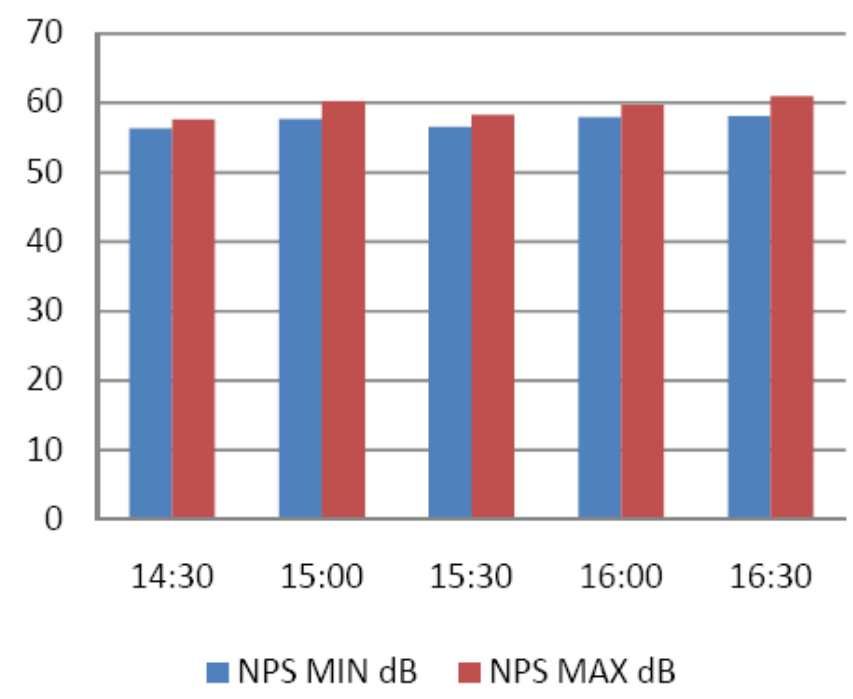

Figura 16 - Relação entre valores de níveis de ruídos máximo e mínimo mensurados no período da tarde.

A Figura 17 mostra a relação entre as medidas obtidas no período noturno:

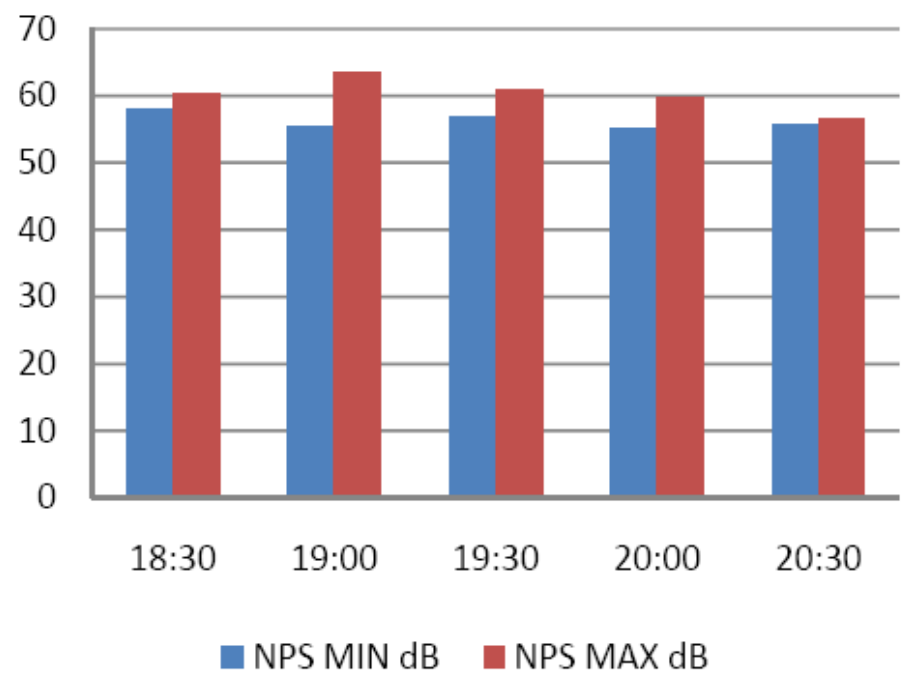

Figura 17 - Relação entre valores de níveis de ruídos máximo e mínimo mensurados no período da noite.

No quinto dia, com 24 pessoas em média freqüentando a biblioteca, os valores mínimos estiveram entre 55,3 e 59,4 dB's, enquanto os máximos entre 56,5 e 65,4 dB 's. Observando que as faixas de valores de níveis de pressão sonora se mantiveram sempre acima de $50 \mathrm{~dB}^{\prime}$ s.

Média Geral em cada um dos turnos das medições: 
Tabela 8- Médias de cada turno durante as cinco medições.

\begin{tabular}{c|c|c|c|c|c|c}
\cline { 2 - 7 } & \multicolumn{2}{c|}{ MANHÃ } & \multicolumn{2}{c}{ TARDE } & \multicolumn{2}{c}{ NOITE } \\
\cline { 2 - 7 } & \multicolumn{5}{c}{ MPS (dB) } \\
\cline { 2 - 7 } & MÍN & MÁX & MÍN & MÁX & MÍN & MÁX \\
\hline 1 & 57,28 & 63,34 & 58,62 & 65,94 & 59,2 & 66,24 \\
\hline 2 & 58,42 & 63,4 & 58,16 & 62,28 & 57,66 & 60,44 \\
\hline 3 & 57,5 & 61,18 & 58,92 & 63,1 & 58,76 & 64,78 \\
\hline 4 & 57,42 & 61,46 & 56,02 & 60,44 & 55,9 & 60,06 \\
\hline 5 & 57,56 & 62,22 & 57,34 & 59,36 & 56,18 & 60,2 \\
\hline
\end{tabular}

Os valores da Tabela 1 foram obtidos através do cálculo da média entre valores mínimos da cada dia e também dos valores máximos de cada dia de acordo com o turno da medição.

A Figura 18 mostra as médias dos valores obtidos nas medições realizadas no turno matutino:

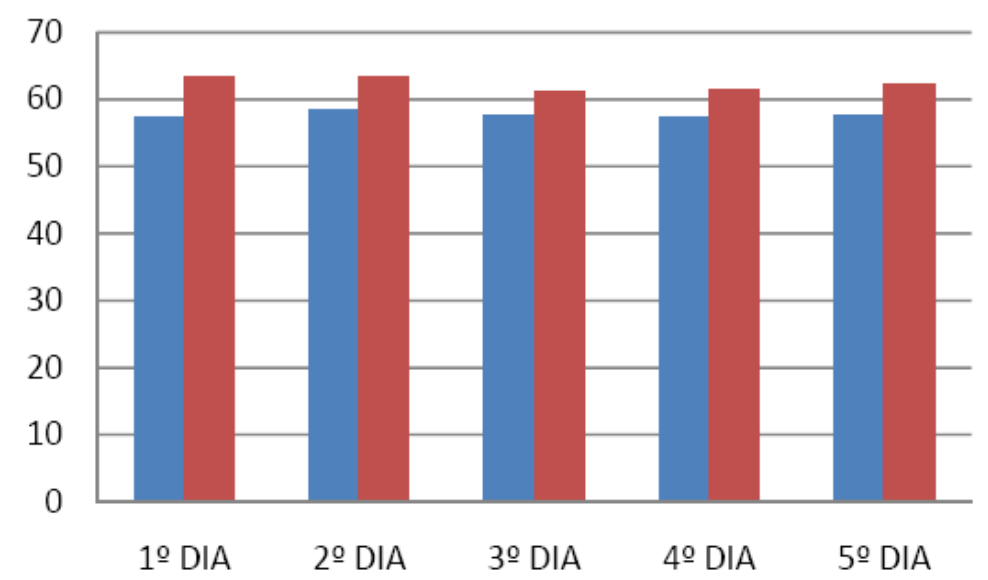

NPS MIN dB NPS MAX dB

Figura 18 - Relação entre valores de níveis de ruídos máximo e mínimo mensurados no período matutino.

De acordo com os valores médios do turno matutino, observa-se na Figura 18 que os mínimos mantiveram-se na faixa de 50 a $60 \mathrm{~dB}$ 's, durante os cinco dias de medições, 
enquanto os máximos mantiveram-se sempre acima de $60 \mathrm{~dB}$ 's. Estes valores encontram-se fora da faixa estabelecida pela legislação, como mostra a Tabela 2 (seção 2.3).

A Figura 19 apresenta as médias dos valores obtidos nas medições realizadas no turno vespertino:

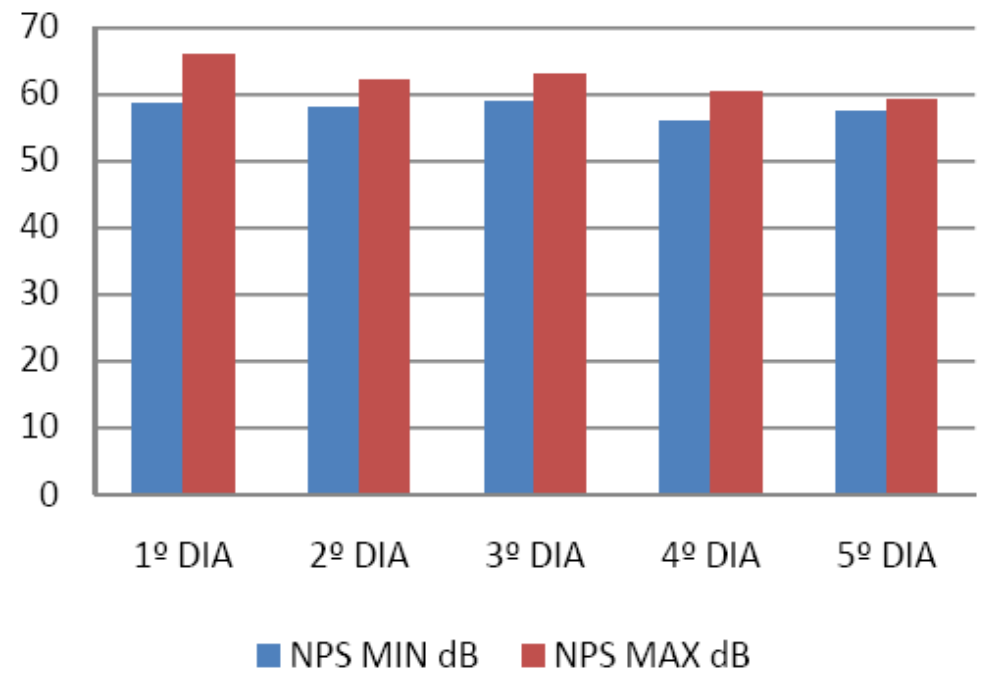

Figura 19 - Relação entre valores de níveis de ruídos máximo e mínimo mensurados no período da tarde.

Como mostra a figura 19, durante os períodos vespertinos as medições apresentam valores mínimos na faixa 50 a 60 dB's, já os máximos encontram-se na faixa de $59-70$ dB's. Ou seja, valores muito altos se comparados com os valores de referência, como pode ser vistos na Tabela 2.

A Figura 20 mostra as médias dos valores obtidos nas medições realizadas no período noturno: 


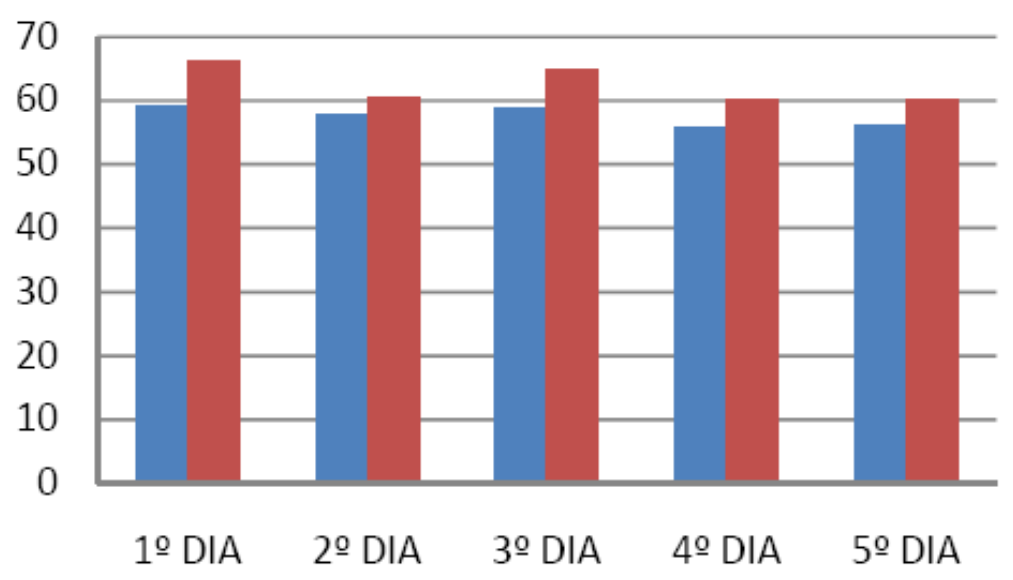

NPS MIN dB $\quad$ NPS MAX dB

Figura 20 - Relação entre valores de níveis de ruídos máximo e mínimo mensurados no período da noite.

Durante o período da noite, as faixa de valores mínimos, assim como nos outros turnos encontra-se entre 50 e $60 \mathrm{~dB}$ 's, enquanto que os valores máximos encontram-se na faixa de 60 - 70 dB's porém, com valores mais próximos de 60 dB's. Os valores medidos no período noturno, também encontram-se fora da faixa de valores aceitáveis mostrado na Tabela.

\section{Comparação com os valores da NBR 10152:1987}

Conforme exposto anteriormente, para desenvolvimento do trabalho, foram efetuadas medições acústicas no salão de leitura (térreo) em cada um dos turnos de funcionamento da biblioteca e, a partir dos resultados obtidos, construiu-se a Tabela 9 apresentando a média geral dos turnos matutino, vespertino e noturno:

Tabela 9 - Média geral em cada turno.

\begin{tabular}{cccc}
\hline Turno de medição & Média de ruídos & $\begin{array}{c}\text { Faixa de ruído } \\
\text { recomendado pela } \\
\text { ABNT }\end{array}$ \\
\hline Manhã & MíNIMO & MÁXIMO & \\
Tarde & 57,64 & 62,32 & $35-45$ \\
Noite & 57,81 & 62,22 & \\
\hline
\end{tabular}

Observou-se que o local aferido excede o nível mínimo de ruído recomendado pela NBR 10152:1987 para uma biblioteca. O valor mínimo nos períodos da manhã tarde e noite excede em aproximadamente 64,7 \% os níveis mínimos recomendados pela NBR 10152, 
enquanto o valor máximo excede em aproximadamente $38,4 \%$ estes níveis mínimos recomendados.

Com estes resultados, constatou-se que o salão de leitura necessita de intervenções emergenciais, como objetivo de melhorar as condições de conforto acústico, bem como as atividades desenvolvidas na biblioteca.

\section{Resultados dos Questionários}

Paralelamente às medições, foram aplicados cerca de 60 questionários para obter opiniões dos usuários da biblioteca a respeito dos níveis de ruído. Essa etapa foi muito importante, pois os usuários praticamente desconhecem a existência da legislação que regulamenta os níveis de conforto acústico em bibliotecas. Assim, foi possível obter uma resposta bem natural por parte dos alunos que responderam o questionário.

Com a aplicação deste questionário buscou-se, além da opinião dos alunos sobre as características do ambiente interno à biblioteca, avaliar se os mesmos apresentavam alguns sintomas comuns durante exposição aos elevados níveis de ruído, o que pode afetar consideravelmente o desempenho de qualquer pessoa que esteja exposta aos mesmos.

Ao analisar estes resultados, também é preciso levar em consideração a fisiologia de cada pessoa, pois as reações ao nível excessivo de ruído podem variar de pessoas para pessoa, fazendo com que as características apresentadas por umas não necessariamente afetarão outras, já que cada um pode responder de forma diferente aos estímulos do ambiente, apresentando um maior grau de adaptação.

\section{Primeira questão}

A primeira questão buscou saber dos usuários o que eles acham do nível de barulho na biblioteca. Utilizou-se aqui a palavra barulho, ao invés de ruído, pra evitar outras interpretações acerca do objetivo almejado na pergunta.

A Figura 21 apresenta o percentual das respostas da questão 1: 


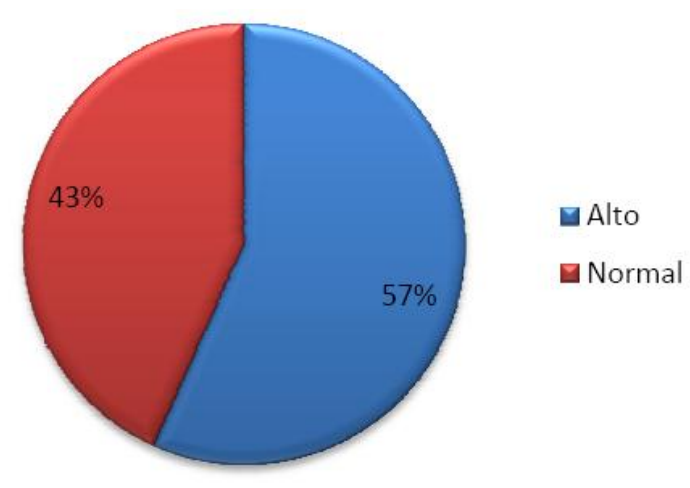

Figura 21 - Percentual das respostas da questão 1.

De acordo como o resultado apresentado no gráfico da Figura 21, é possível notar que mais da metade dos alunos, 57\%, que responderam o questionário acham que o nível de barulho é alto, enquanto que $43 \%$ responderam que acham os níveis normais. $O$ fato das medidas terem sido obtidas em horários específicos, sendo que os mesmos englobam desde os mais movimentados a outros em que o movimento é menos intenso, justifica um considerável equilíbrio nas respostas apresentadas.

\section{Segunda questão}

A segunda questão, em complemento à primeira, buscou saber dos alunos se os níveis associados à questão anterior, segundo sua concepção, eram adequados para o estudo na biblioteca.

A Figura 22 mostra o percentual das respostas da questão 2:

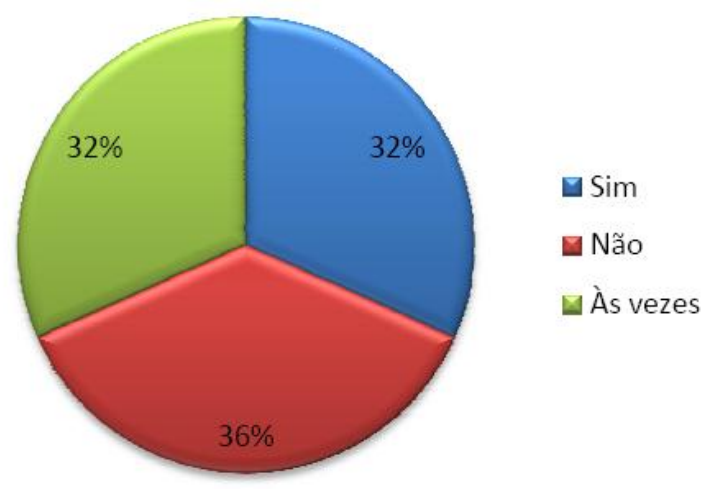

Figura 22 - Percentual das respostas da questão 2.

Ao analisar o gráfico da Figura 22, tem-se que 32\% acham que o ambiente é adequado para o estudo, $36 \%$ não acham o ambiente adequado e $32 \%$ às vezes acham que sim e outras que não. Relacionando estas informações, concluiu-se que a maioria dos alunos desconhece a legislação sobre os níveis de conforto acústico em bibliotecas e também que os mesmos já estão acostumados com o barulho apresentados no ambiente interno da biblioteca. 


\section{Terceira questão}

A terceira questão foi dividida em alguns itens e objetivou saber como os alunos se sentem quando estão freqüentando a biblioteca.

O principal objetivo desta questão foi verificar se os alunos apresentam algumas das características comuns às pessoas que estão expostas a determinadas faixas de ruídos, tais como: falta de concentração, dificuldades de memorização, irritação, indisposição, insônia.

\section{Item A}

Este item busca avaliar o desempenho do aluno quando exposto aos níveis de ruído no ambiente da biblioteca.

A Figura 23 apresenta o percentual das respostas do item A

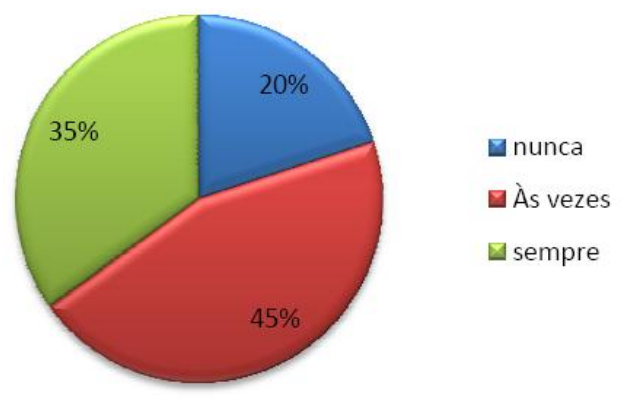

Figura 23 - Percentual das respostas do item A.

Analisando o gráfico da Figura 23, é possível notar que $20 \%$ dos alunos que responderam o questionário não sentem diminuição no desempenho dos estudos quando sujeitos aos níveis de ruído apresentados na biblioteca, 35\% sempre tem o desempenho afetado de forma negativa durante a permanência na biblioteca e $45 \%$ algumas vezes tem o desempenho dos estudos afetados e outras não.

Vale ressaltar que os parâmetros de análise para o desempenho nos estudos variam muito entre cada um dos alunos. Enquanto algumas pessoas têm maior facilidade de concentração, outras não possuem essa característica, sendo diretamente afetadas pela presença de ruído excessivo.

\section{Item B}

Este item pretende questionar o aluno em relação ao processo de memorização ou fixação do conteúdo estudo.

A Figura 24 mostra o percentual das respostas do item B: 


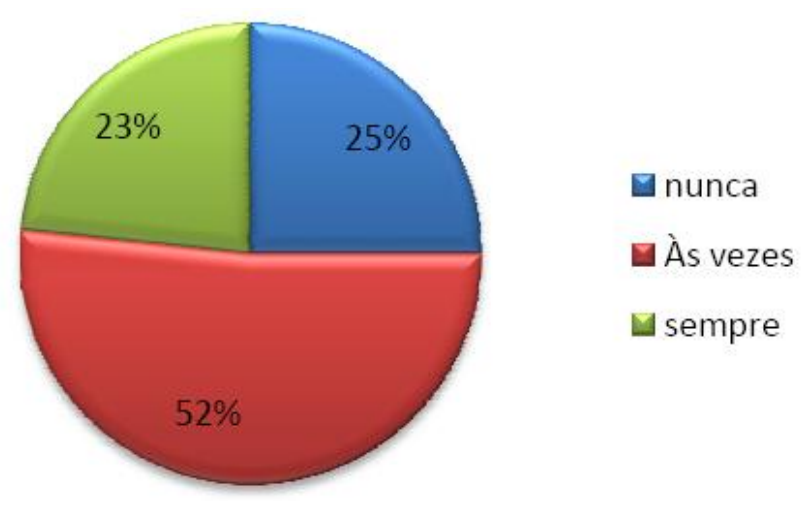

Figura 24 - Percentual das respostas do item B.

Pode-se notar, pelo gráfico da Figura 24 , que $25 \%$ não possuem dificuldade de memorização, $23 \%$ sempre tem dificuldade e 52\% apresentam dificuldades de memorização algumas vezes e outra não. Os resultados deste item podem ser justificados pelas mesmas razões do item $A$, pois cada pessoa apresenta uma fisiologia diferente o que pode diminuir os efeitos do ruído e não permitir que este interfira na sua memorização e ou assimilação.

\section{Item C}

Este item analisa um dos mais importantes fatores que interfere no processo de aprendizagem, que é a concentração:

A Figura 25 apresenta o percentual das respostas do item C:

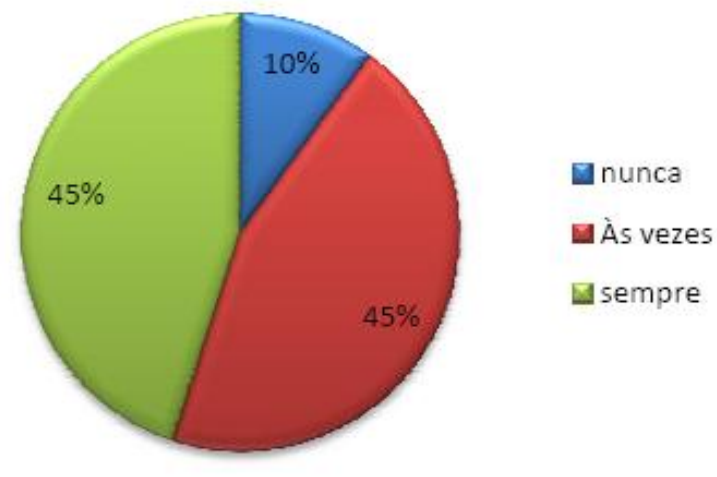

Figura 25 - Percentual das respostas do item C.

Nota-se, pelo gráfico da Figura 25 , que apenas $10 \%$ dos alunos nunca sentem falta de concentração, $45 \%$ sempre tem sua concentração afetada pelos níveis de ruído mesurados e outros $45 \%$ às vezes sentem-se afetados e outras não.

A concentração é importante, e preocupa o fato de que esta seja prejudicada em um ambiente onde deveria ser prioridade. 


\section{Item D}

Este item procurou abordar os alunos sobre a irritação, que é uma das características causadas pela presença dos elevados níveis de ruído.

A Figura 26 mostra o percentual das respostas do item D:

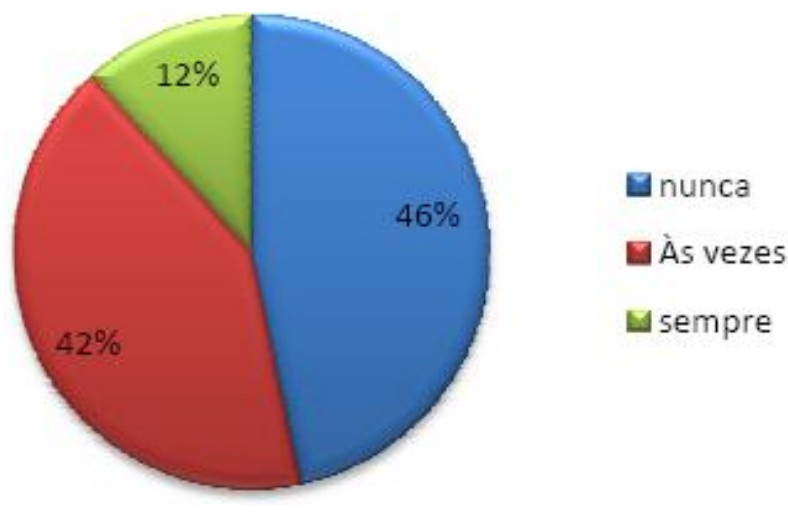

Figura 26 - Percentual das respostas do item D.

Como é possível observar no gráfico da Figura $26,12 \%$ dos alunos entrevistados, sentem algum tipo de irritação sempre que freqüentam a biblioteca, $42 \%$ às vezes sentem e $46 \%$ nunca ficam irritados devido aos níveis de ruídos apresentados na biblioteca.

\section{Item E}

Este item trata sobre a indisposição, outro fator relevante que afeta diretamente a aprendizagem adequada do aluno.

A Figura 27 apresenta o percentual das respostas do item $\mathrm{E}$ :

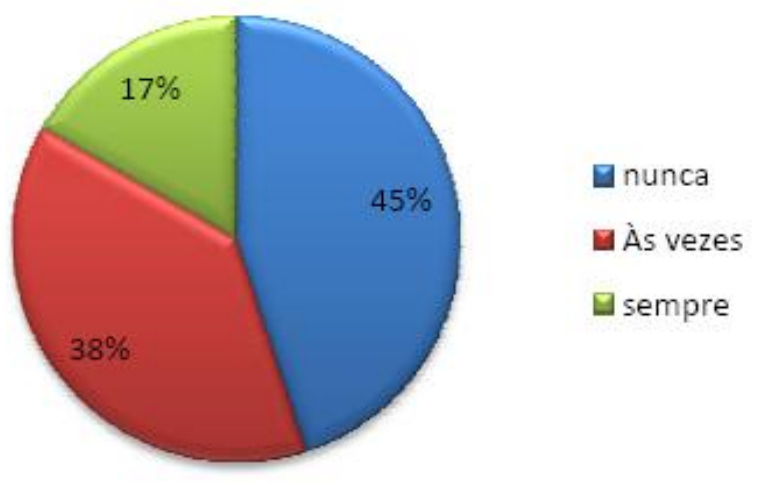

Figura 27 - Percentual das respostas do item E.

Segundo as informações coletadas no gráfico da Figura 27, 17\% dos alunos sempre apresentam indisposição quando submetidos ao barulho presente na biblioteca, $38 \%$ dos alunos às vezes ficam indispostos e $45 \%$ alegam não sentir indisposição devido ao barulho na biblioteca. 


\section{Item F}

O item $\mathrm{F}$ apresenta os resultados sobre insônia, outra característica de quem está sujeito à exposição de níveis excessivos de ruídos.

A Figura 28 mostra o percentual das respostas do item F:

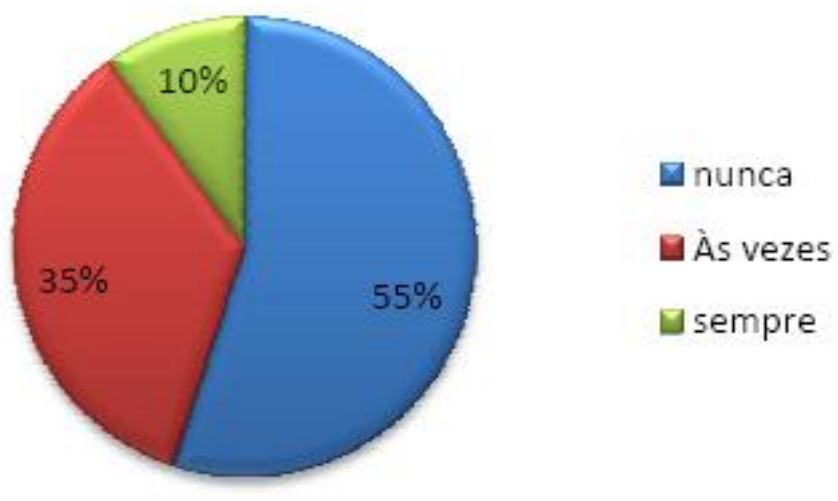

Figura 28 - Percentual das respostas do item F.

Os elevados níveis de ruído também interferem no sistema fisiológico das pessoas causando insônia. Quando submetidos a excessivos níveis de barulho esta característica manifesta-se. Observando o gráfico da Figura 28, 55\% dos alunos que responderam o questionário não apresentam insônia devido ao excesso de ruído, 35\% às vezes apresentam insônia e 10\% alegam que sempre sentem insônia.

\section{CONSIDERAÇÕES FINAIS}

Após a coleta e análise dos dados obtidos, fica evidente que apesar dos altos níveis de ruídos observados, as preocupações dos responsáveis pela manutenção da salubridade, ou seja, do conforto adequado neste ambiente, ainda é incipiente. Assim, fica evidente que o ambiente da biblioteca Tebyreça de Oliveira avaliado não se encontra em condições apropriadas para garantir o conforto acústico de seus usuários. Existem também interferências, devido à falta de tratamento acústico, de fatores externos, tais como: sirene de alerta da troca de horários de aulas, porta de acesso, telefone e de ar-condicionado. Enfim, o que realmente sobressai é a falta de conscientização dos freqüentadores deste recinto, fato que pode ser justificado pela ausência de campanhas permanentes em favor do silêncio, o que leva infelizmente a resultados aquém dos desejados em comparação com os resultados recomendados pela NRB 10152 para os níveis de conforto acústico. Este trabalho foi uma ferramenta mais de análise do que de controle, pois o barulho permanece, podendo ser subsídios para estudos de novas metodologias de controle e implantação de ações que busquem minimizar os impactos do ruído ocupacional. 


\section{REFERÊNCIAS BIBLIOGRÁFICAS}

1. MILANESI, Luis. O que é Biblioteca. Editora Brasiliense. 9ạ Ed. São Paulo. p. 111.

2. LEITE, José Yvan Pereira, et al. Nível de Ruído - Uma Medida de Qualidade nas Bibliotecas. Associação Brasileira de Engenharia Sanitária e Ambiental. Trabalhos técnicos. Rio de Janeiro, ABES, 1997, p.9 Mapas, Tab.

3. SILVESTRE, Maria Rosa, Aproximação à relação carga/desgaste no processo de trabalho odontológico. Monografia - UNB. Brasília. 1992. p. 11-15

4. RIOS, A. N. Efeito do Ruído Tardio na Audição e na Qualidade do Sono em Indivíduos Expostos a Níveis Elevados. Ribeirão Preto, 2003. Dissertação (Mestrado). Faculdade de Medicina da USP/Ribeirão Preto.

5. NBR10152-Níveis de ruído para conforto acústico - ABNT. 1987

6. MOTA, Suetônio. Introdução a Engenharia Ambiental :Poluição Sonora.Disponível em: http://www.analgesi.co.cc/html/t33335.html. Acesso em: 17 jun. 2011

7. FERNANDES, J.C. - O Ruído Ambiental: Seus Efeitos e seu Controle - Apostila do Departamento de Engenharia Mecânica da UNESP - Campus de Bauru, 1994. 